\title{
Does Gove Really Want to Set Us Free?
}

\author{
JON BERRY
}

\begin{abstract}
This article argues that one of the central paradoxes of neo-liberalism is currently being played out in the UK Coalition Government's education policy. Rhetoric that talks of freedoms to be enjoyed by schools and teachers is at variance with a centrally imposed, reductive view of the curriculum, continuing high-stakes scrutiny and the forcing of schools towards academy status. The coalition's hastily constructed legislation reveals a view of education that bears the hallmark of pragmatic marketisation with such limited freedoms as may be enjoyed existing in the context of reward for the compliant and acquiescent. The article concludes with a brief - and necessary - consideration of possibilities for resistance.
\end{abstract}

The Conservative Party will give you freedom to teach bow you want to.

(Michael Gove, Speech to Association of Teachers and Lecturers, Conference 2010 [ATL, 2010])

There is no calling more noble, no profession more vital and no service more important than teaching.

(Foreword to the White Paper, The Importance of Teaching

[Department for Education (DfE), 2010])

When it came to education, the Coalition Government that found itself in office in May 2010 was in a hurry. Fifteen days after the formation of the coalition itself on 10 May, the Queen's Speech promised that 'legislation will be introduced to enable more schools to achieve academy status, giving teachers greater freedom over the curriculum and allow new providers to run state schools' (Number 10, 2010). On the same day, all schools with an Ofsted 'outstanding' rating were written to inviting them to consider applying for Academy status. The Coalition's 17-point plan for education was published the day after, on 26 May (The Coalition, 2010) and on 27 May the Academies Bill was first debated in the House of Commons. Some 39 working days later this became an Act (Academies Act, 2010), thereby leaving in its wake the Terrorism Prevention and Investigation Measures Bill which had first been 
debated on 23 May but did not complete its passage through the Houses until 14 December. Underpinning such haste was the unequivocally expressed need to accelerate liberation for schools and teachers. The promise was explicit:

Ministers are committed to giving schools more freedom from unnecessary prescription and bureaucracy. They have always made clear their intentions to make changes to the National Curriculum that will ensure a relentless focus on the basics and give teachers more flexibility than the proposed new primary curriculum offered. (DfE, 2010)

The notion of 'basics' is, we are to believe, a matter of obvious common sense and one imagines that such a confident assertion would not be seen as ironic by the authors. That the Coalition conflates the academies programme with freedom - often in a way in which there is no discernible connection within the argument - is one of the hallmarks of its legislative programme. Another is the enduring paradox of neo-liberalism that requires the coexistence of a distrust of state power along with the existence of a state that is prepared to be coercive when it deems it necessary to protect such individual freedoms (Harvey, 2005). For the market and free enterprise to flourish - and we should be in little doubt that the academies project is a manifestation of a commitment to such a doctrine - the state has to determine the conditions in which they can do so. The Coalition's haphazard elision of a commitment to greater autonomy against a background of unremitting control and scrutiny is a characteristic that resurfaces throughout their proposals.

This article examines four of the principal staves of the Coalition's proposals. These are the Academies Act (Academies Act, 2010); the Schools White paper - The Importance of Teaching (DfE, 2010), Teachers' Standards (DfE, 2011a) and Training Our Next Generation of Outstanding Teachers (DfE, 2011b).

\section{The Academies Act}

The Academies Act consists of 20 provisions with numerous sub-divisions in each, along with two subsequent Schedules dealing with the technicalities of implementation. Curricular provision is mentioned only once (p. 2) and in the most general of terms, referring only to the requirement of an academy to provide a curriculum that is balanced and broadly based. Teachers are not mentioned and there are only three references to head teachers, all of which are in terms of the requirement for future 'proprietors' of schools to inform the Secretary of State of particular developments. Beyond this, the Act concerns itself almost exclusively with the establishment of an apparatus that enables Academies to act as independent financial entities. Among these provisions, further sections deal in turn with aspects of centralised financing, the transfer of surplus funding from local authorities, arrangements for property transfer and, beyond these, the remaining sections concern themselves with technical implementations and arrangements. Significantly, among these technicalities is 
the automatic granting of charitable status - 'a qualifying Academy proprietor is a charity' (p. 7) - thereby replicating the advantages in terms of taxation benefits enjoyed by independent schools in England.

The Act does not concern itself directly with curriculum, teachers or students; it is about creating the circumstances in which those charged with the running and organisation of schools are afforded greater freedom and responsibility to do so at a managerial level. Notwithstanding a degree of irony in the fact that such freedom is granted at the behest of a centrally situated Secretary of State - whose powers and responsibilities are referred to on 51 occasions in the Act - the legislation concerns itself principally with the stripping away of any fiscal and organisational responsibility from local authorities. Mentioned on 27 occasions in the Act, 10 of the provisions for local authorities deal with the transfer of land away from these bodies, six with the need to transfer funds to proprietors and three to other instances of the ceding of powers. As an aside to these observations, the Act requires that consultation around conversion need take place only with such persons as are deemed appropriate (p. 5), in contrast to the requirements placed on a local authority within democratic structures that govern the actions of other community schools. However, if the Act is instrumental mainly in terms of putting in place the apparatus for organisational freedom and autonomy, it is in the subsequent legislation of the schools' White Paper that the argument about freedom 'to teach how you want to' comes to the fore.

\section{The Schools' White Paper: The Importance of Teaching}

The White Paper immediately and unequivocally locates educational provision as a function of economic growth while simultaneously promoting the academies programme through a discourse dominated by this preferred structural framework. Two separate forewords are provided, the first signed by the Prime Minister and his Coalition Government Deputy and the second by the Secretary of State for Education; both make illuminating reading in terms of identifying the thrust of this legislative programme. Parts of the opening paragraph from the Prime Minister are worth citing at some length:

What really matters is how we're doing compared with our international competitors. That is what will define our economic growth and our country's future. The truth is, at the moment we are standing still while others race past. In the most recent OECD PISA survey in 2006 we fell from 4th in the world in the 2000 survey to 14 th in science, 7 th to 17 th in literacy, and 8th to 24 th in mathematics.

The key to improving this situation is, we are told, to train, recruit and retain the best teachers. In a somewhat peculiar expression, the document talks of 'teaching standards [that] have increased (p. 3, my emphasis) before expressing the need to enhance the status of teaching as a profession. From here, it talks 
immediately about strengthening the disciplinary powers of teachers which will be underpinned by a greater school autonomy that, in itself, will be the result of freedoms enjoyed under the academies programme. Comments acknowledge the need to 'devolve as much power as possible to the front line' (p. 3) and make an apparently seamless connection between this and the conversion to Academy status which, in its turn, will liberate schools from bureaucratic burdens through 'a streamlined and effective accountability system' (p. 4). How the mechanics of these disparate connections will work is not touched upon.

In the second foreword from the Secretary of State, the tone differs and leans noticeably towards a vision of education located more closely in the liberal humanist tradition, talking of giving children the 'chance to take their full and equal share in citizenship, shaping their own destiny, and becoming masters of their own fate' and of education 'allowing individuals to choose a fulfilling job, to shape the society around them, to enrich their inner life' (p. 6). At the heart of this vision, the teacher is envisaged as 'society's most valuable asset' (p. 7). What neither of these forewords address is how the greater freedom and autonomy afforded to either schools or teachers - the terms seem to be interchangeable at this stage - will be effected by anything other than structural changes that, although freeing educators (in whatever form) from centralised control, will also hold them accountable to centralised power. What follows in the body of the text does little to disentangle this confusion and concomitant non sequiturs.

The lack of clarity in this legislation becomes more marked the further one reads into the documentation. The following extract from the Executive Summary is instructive in this respect:

There are many outstanding school teachers and leaders. But teachers consistently tell us that they feel constrained and burdened, required to teach the same limited diet to successive classes of young people. Most children and young people behave well, but teachers consistently tell us that their authority to deal decisively with bad behaviour has been undermined. More children are participating in education for longer, but the curriculum they are following contains too much that is non-essential and too little which stretches them to achieve standards matching the best in the world. (p. 8)

The line of argument is difficult to follow here and is illustrative of the conflation of ideas and confusion referred to above. Leaving aside the omission of any reference to the source of those teachers who 'consistently tell us' that they feel constrained in their teaching, the immediate elision of this observation with the problems of poor behaviour is of great interest, apparently acknowledging the link between curriculum provision and behaviour that was identified by Dewey over a century ago (Dewey, 1902) and resolutely ignored by policy makers in the intervening decades. Then, in a further twist, we are referred to the idea of 'non-essential' content - to which we shall return shortly - and thence to the need to keep pace with international economic competitors. 
What follows now, by way of further, more detailed explanation, underlines the central paradox of how, 'having freed schools from external control', there remains a need to 'hold them effectively to account for the results they achieve' (p. 8). At the core of this argument sits this contradiction: the exhortations towards taking greater, more autonomous and authoritative control are articulated simultaneously with prescriptive direction within a framework of high-stakes scrutiny. This is illustrated most clearly when the White Paper, within a few paragraphs (pp. 10-11) reiterates the idea that too much of what is taught in schools is non-essential while going on to state the Government's intention to 'specify a tighter, more rigorous model of knowledge which every child should expect to master' by a certain age. The 'greater autonomy' - the details of which remain unspecified - that schools will enjoy under this regime, will, along with the use of recognised 'benchmarks', be instrumental in avoiding 'a prescriptive straightjacket into which all learning must be squeezed.' The set of clear directives that immediately follows raises the question of how, precisely, this may be the case. There will be an emphasis on 'core subjects' and the use of the teaching of synthetic phonics 'as the best method for teaching reading.' The introduction of the English Baccalaureate, with five or six set subject areas, will be a benchmark for the success of secondary schools. Age-related testing, with results made public, will remain the chief tool for judging school effectiveness. Beyond these measures, 'gaming behaviour' (p. 13), whereby schools overrehearse for vital tests or manipulate examination entries and outcomes to enhance and demonstrate successes, will be addressed by putting 'far more information into the public domain' and through the 'reform of league tables.' Many teachers already find it difficult to understand how any professional autonomy can be exercised while league tables that rely largely on unmediated raw material are in place: the White Paper's commitment to reformed tables with even more information available holds the prospect of an even more directed drive towards the production of even more desired outcomes.

A section dealing with pupil behaviour is worth taking some time to consider along with a reflection of the prominence given to this and the importance placed on it in this documentation. To treat it with such due regard is entirely understandable, albeit that, characteristically, the government view invokes a golden age of teacher authority that needs 'restoring' (p. 32) in its approach to this issue. However, the proposed measures reveal much about the precepts and preoccupations of the legislators. Immediate reference is made to powers of search and the use of force - echoing a predilection for a discourse around authority implicit in the encouragement of members of the armed forces to be drafted into the teaching workforce (p. 22). The encouragement to take strong stands against bullying behaviour and the use of detention are already regarded by most teachers as an unremarkable part of their daily routine. One is left to reflect on the lack of understanding evinced by such proposals in terms of teachers' daily working lives, with such comments failing to recognise the energy that most teachers expend in implementing these measures without the need of such prompts from a distance. The documentation comes closest to 
addressing these concerns when it talks, in terms however vague, of the daily, unspectacular disruption that blights the lives of many professionals. Referring to an uncertainty among teachers about the extent of their powers (like so much of the documentation, the origins of such comments are not touched upon), it promises to 'strengthen and simplify the existing position and powers, ensuring that teachers feel supported and protected when they address difficult behaviour' (p. 33). The extent of this assurance is developed only in one further comment, which promises to enable "Head teachers to support their teachers to maintain good discipline in the classroom every day by establishing a whole school culture that promotes respect, safety and good behaviour' (p. 34). At no point in this section does the legislation make any correspondence between enhancing the authority - or autonomy - of a teacher through granting that teacher any greater influence over what is taught, the rationale behind such decisions or the methodology employed for any subsequent implementation. For the legislation to ignore such a basic connection - one that is at the centre of much advice given to those at the very start of teacher education courses - is a rather extraordinary omission.

What follows in the examination of those parts of this paper that are concerned with training and recruitment of teachers, along with the further discussion document on 'training' and standards (DfE, 2011a, b), is a conceptualisation of teachers and teaching that fits the neo-liberal paradigm of measurability aligned to accountability, the primacy of market forces and the hand of the state to steer the course in the event of mishap.

The 12-page section on Teaching and Leadership (pp. 19-31) places most of its emphasis on the establishment of structures that 'will free schools from externally imposed burdens and give them greater confidence to set their own direction' (p. 31). Beyond this assertion, no detail is given, other than an undertaking not to impose central templates for lesson planning (p. 30), which do not, in fact, currently exist. There is little else that has an impact on serving teachers other than measures mooted to help them 'renew their passion' (p. 24) by applying for professional development through schemes, the funding for which potential applicants will have to compete. The centrality of competitive market forces is reinforced by an unequivocal commitment to payment for 'good' performance and the use of bursaries and extra payments as incentives for those willing to fill posts in curriculum areas that have become difficult to fill principally in mathematics and science. The section provides facility for head teachers to exercise discretionary payments and to pay off the student loans of prospective teachers. In a telling illustration, pay and pay flexibilities are mentioned on a dozen occasions and, in a section in which teaching forms part of the title, the terms 'curriculum', 'theory' and' pedagogy' are entirely absent.

While these terms are not employed, the section makes 15 mentions of the term 'practice', preceded on each occasion by either 'good', 'best' or 'effective'. This emphasis is indicative of the policy's promotion of school-based training and the elevation of some schools to the status of Teaching Schools (p. 20). 'On the job' training is mentioned on four occasions and there are 10 references to 
the charitable organisation Teach First, which recruits highly-qualified graduates, often on a short-term basis, to teach in challenging schools, having undergone no formal training. While 'some of the best higher education providers of initial teacher education' (p. 23) may be invited to participate in the process of training teachers, the role of such institutions appears to be limited.

What emerges from this document, which ostensibly expresses the need to place the teacher at the centre of the educational process, appears to be the conception of that same teacher as a craft-oriented techno-rationalist, learning that craft at the elbow of those well acquainted with an accepted version of 'best' or 'effective' practice - a situation highly redolent of Bourdieu's notion of the replication of culture. As we turn to look at the set of revised standards for teachers formulated by the Coalition Government, this concept seems to be further reinforced.

\section{Teachers' Standards}

The White Paper promises to look at the Standards for Qualified Teacher Status (QTS), noting that there are 33 such Standards, 'only one of which focuses solely on teaching and learning' (DfE, 2010, p. 26). It goes on to give the assurance that the new standards will have a 'stronger focus on key elements of teaching, including: the best approaches to the teaching of early reading and early mathematics, how best to manage poor behaviour, and how to support children with additional needs, including Special Educational Needs' (p. 26). The revised Standards are framed under eight main headings with a number of subsections, amounting ultimately to 35 requirements along with an addendum on professional conduct. The preamble to the section on the Standards makes it clear that adherence to them is a professional requirement that has implications for pay and career progression, stating explicitly that "we are proposing that teachers' performance will be assessed against the standards as part of new performance management arrangements in schools' (DfE, 2011a, p. 3).

The 'stronger focus' on specific elements of teaching is embodied in two particular directives. The first of these is the requirement when 'teaching early reading' to 'demonstrate a clear understanding of systematic synthetic phonics' (p. 6) and the second is the less prescriptive need when teaching early mathematics to 'demonstrate a clear understanding of appropriate teaching strategies' (p. 6). Children's learning is only mentioned on two occasions, with only one reference to teachers demonstrating an understanding of how this takes place (p. 6). Reference to pedagogy and learning theories are completely absent and there is one reference to the need to be aware of children's social and intellectual development. There is one mention of a requirement for teachers to contribute to the design of 'an engaging curriculum' (p. 7), with all other reference to the term being made in the context of teachers having knowledge of current curricula.

The undertaking to strengthen the focus on how best to manage poor behaviour' is difficult to locate. It is worth looking in some detail at any precise 
development from previous Standards that exemplifies this promised reinforcement. The previous requirement for teachers had been embodied in two Standards that articulated the need to "establish a purposeful and safe learning environment conducive to learning and identify opportunities for learners to learn in out-of-school contexts' along with the necessity to 'establish a clear framework for classroom discipline to manage learners' behaviour constructively and promote their self-control and independence' (Teacher Development Agency). Other than an extrapolation of the central ideas embedded in these expectations, the revised Standards appear to cover the same ground and express the same central concerns when they exhort teachers to have clear rules and routines for behaviour in classrooms, have high expectations of behaviour and establish a framework for discipline, manage classes effectively and maintain good relationships with pupils. There is little here to distinguish between these 'new' standards and the apparently cumbersome and restrictive ones that they are intended to replace.

When one looks at aspects of the impetus and direction of these initial policies of the Coalition Government what is revealed is an apparent discarding of theoretical knowledge, a preference for on-the-job training and a seemingly populist emphasis on the imposition of firm discipline as the basis for such policy. This seems to be underlined in the following section that scrutinises plans for initial teacher education.

\section{Training our Next Generation of Outstanding Teachers}

Comment about this government discussion document (DfE, 2011b) is worthwhile because of the way in which it reinforces the idea of teaching and education as being projects that are driven by a notion of the production of human capital. The measures proposed cannot be disaggregated from a discourse of value for money, accountability and measurability underwritten by a topically all-pervasive societal discourse around the requirement to cut public expenditure. The need to make 'better investment' (p. 8) predominates in much of the document in which, in an expression of (one imagines) unintended banality, the need to provide training that is more effective in preparing trainees to be successful in the classroom' (p. 3) is the expressed intention. The slight on current provision, intended or otherwise, is implicit.

The document reiterates the White Paper's confidence in the efficacy of the Teach First scheme, reminds the reader of the need to keep pace with international competitors and restates the central importance of the use of synthetic phonics and the need to maintain orderly behaviour. Once again, the structural changes embodied in the Academies Act are seen as the instrument which will enable progress to be made on these fronts along with the recruitment and retention of a stronger teaching force, notwithstanding a recognition of the fact that "we have in our schools today the best generation of teachers we have ever had' (p. 3). This already strong professional body will be enhanced by a recruitment process that will become more rigorous and 
thorough and will be 'incentivised' (p. 10) by such measures as targeted training bursaries and a more open market to allow an expanded range of 'high quality providers into the system' (p. 10). Further to this, training providers will need to put their employability record into the public domain as 'an incentive to encourage better retention rates' (p. 10).

Central to the case of the need for the reform of teacher training is the argument promoted in the document that 'there are some general lessons about what makes for the best quality provision' (p. 13) and, consistent with the policy preference for school-based training, this approach enjoys continuing advocacy. To substantiate this claim, work by Musset et al (2010) is cited on three separate occasions (p. 13). The layout of the document does not include details of this or any other reference; all such citations are simply identified in footnotes. Musset's work is notable for two reasons. The first is that the European countries on which her findings are based do not include England or another UK country. The second is the fact that it is relatively difficult to locate - a difficulty noticed and shared by The Times Educational Supplement (2011). However, work by Menter (2010) which identifies the finding that 'where teachers have extensive initial training in schools, they perform better' has defeated the searching efforts of this writer. An email exchange in September 2011 confirmed that the author himself was no clearer about the provenance of the reference than myself. Work by Reinhartz \& Stetson from 1999, which, apparently, supports the importance of school-based training, is equally difficult to locate and is not listed on their website at the Texas Christian University. Finally, the simple characterisation of work by Ingvarson et al (2005) as being evidence of the unsurprising fact that 'schools providing learning opportunities have a significant influence on a new teacher's development' (p. 13) is a somewhat misleading summary of wide-ranging Australian research that is not, in fact, confined to new teachers, but deals with the subject of professional development for teachers with more than 10 years' experience (Ingvarson et al, 2005, p. 3).

In a further indication of the lack of importance attributed to theoretical and pedagogical understanding discussed above, the term 'pedagogy' is not used at any point in the document. The only mention of theory is to observe that 'there is some evidence that university-based trainees see their training as too theoretical' (p. 14). There is no indication of any sort as to the source of this evidence. Reference to practice is, once again, widespread, with brief case studies (pp. 14, 17) demonstrating the advantages of schools taking the lead in training teachers. Alongside this a number of financial measures are proposed to make it easier for schools to become involved with training, albeit with an acknowledgement that universities may have some part to play in the process. Principal among the financial arrangements would be an increase in some funding to allow trainees to "take on more teaching responsibilities as they are training' (p. 11) in an attempt to make the employment of such trainees attractive to schools. 
Two central lines of argument run through all of the documentation cited, both of which are prevalent reflections of topical policy: value for money and the privileging of practice over theory, the latter probably representing the triumph, perhaps, of the (contested) notion of common sense. If we are to believe Gove, this benign policy ensemble will cut through overbureaucratisation, address the perils of feeble classroom discipline and rid us of subject matter that lacks challenge and rigour. Setting schools free from the restrictions of an over-centralised curriculum and the sluggishness of local authorities will be the logical consequence of attaining academy status. The argument is clear: it is only those burdened by self-interest and outdated ideology who would obstruct such progress.

It is not the central purpose of this article to delve in any great depth into Gove's personal ideology, albeit that it requires no great perspicacity to believe that the man who extols the virtue of the right-wing think-thank the Centre for Policy Studies as being 'at the heart of the political debate' (Gove, 2009) is someone happy to see the market at the centre of policy. In terms of the freedom that is offered here, it is best characterised as the paradoxical notion of an autonomy that is both earned and coercive in the way in which it holds out the promise of reward for compliance and acquiescence (Quicke, 2000; Whitty, 2007; Beck, 2009; Storey, 2009). The implications in terms of equality of opportunity and, indeed, the enduring influence of class difference in terms of educational provision are clear here. If the apparatus of control - Ofsted and league tables based on narrowly defined outcomes - remain firmly in place, there will continue to be winners and losers. Acquiring the quality measures of the English Baccalaureate will be taken as a given in well-favoured secondary schools who may well find spaces for a degree of curricular freedom - although the common practice of placing young people on the next treadmill of the exam cycle the moment they have completed the previous one may continue to militate against this. Notwithstanding systems which test a child's ability to decode fape and snemp being used to make judgements about schools and teachers, many such schools will ride the wave of this and maintain the centrality of narrative and creativity. But for others, digression from the script means inviting failure in terms of published, public outcomes - and Gove's demonstrable willingness to force Academy status on those who fall foul of the achievement (BBC, 2012) reveals that talk of freedom sits uneasily with such compulsion. When Braverman talks of workers who have the illusion of making decisions by choosing among fixed and limited alternatives designed by a management which deliberately leaves insignificant matters open to choice' (Braverman, 1974, p. 39) this is a perfect characterisation of the actions of the Coalition Government: a limited freedom, it appears, is the reward for doing as you're told.

If it is the case that Gove does not really want to set us free, do we simply comply or die? My own recent research project demonstrates that teachers, despite the unremitting daily reminder to generate measurable outcomes, have not lost sight of a vision of education that goes beyond the somewhat meagre 
current offering (Berry, 2012). We may just also be witnessing a hesitant rebirth of some teacher militancy that could mark the start of some challenge to the hegemony of audit and market forces. Although essentially a defensive action, the ongoing industrial action in defence of teachers' pensions may prompt the opening of a wider interrogation of conditions of service, including their part in curriculum development. The possibility of a boycott of tests based on the synthetic phonics method has been raised by teacher unions. Beyond this, a wider societal discourse about the efficacy of the market may yet begin to influence discourse about education as a whole. As Eagleton (2011, p. xi) pithily suggests when discussing the current economic crisis; 'you can tell that the capitalist system is in trouble when people start talking about capitalism.' The teaching profession can at least be certain of one thing: Gove's talk of freedom certainly does not envisage any form of liberation from the thrall of the very market that imposes the current apparatus of restraint and restriction.

\section{References}

Academies Act (2010) http://www.legislation.gov.uk/ukpga/2010/32/contents/data.htm

Association of Teachers and Lecturers (ATL) (2010) http://www.atl.org.uk/policy-andcampaigns/conference/2010/conference-2010-gove-speech.asp

BBC (2012) http://www.bbc.co.uk/news/education-16409940

Beck, J. (2009) Appropriating Professionalism: restructuring the official knowledge base of England's 'modernised' teaching profession, British Journal of Sociology of Education, 30(1), 3-14. http://dx.doi.org/10.1080/01425690802514268

Berry, J. (2012) An Investigation into Teachers' Professional Autonomy in England: implications for policy and practice. Unpublished $\mathrm{PhD}$ thesis.

Braverman, H. (1974) Labor [sic] and Monopoly Capital. London: Monthly Review Press.

The Coalition (2010)

http://webarchive.nationalarchives.gov.uk/20100919110641/http://programme forgovernment.hmg.gov.uk/schools/index.html

Department for Education (DfE) (2010) The Importance of Teaching: The Schools White Paper.

http://www.education.gov.uk/publications/standard/publicationdetail/page1/C M\%207980

Department for Education (DfE) (2011a) Teachers' Standards: effective from September, 2012. https://www.education.gov.uk/publications/eOrderingDownload/teachers\%20sta ndards.pdf

Department for Education (DfE) (2011b) Training our Next Generation of Outstanding Teachers.

http://media.education.gov.uk/assets/files/pdf/t/training\%20our\%20next\%20ge neration\%20of\%20outstanding\%20teachers.pdf

Dewey, J. (1902) The Child and the Curriculum. Chicago: University of Chicago Press. 
Gove, M. (2009) Speech to Centre for Policy Studies.

http:/ / www.cps.org.uk/index.php?option $=$ com_contentandview $=$ cpsarticleandid $=281$ anditemid $=17$

Eagleton, T. (2011) Why Marx was Right. New Haven: Yale University Press.

Harvey, D. (2005) A Brief History of Neo-liberalism. Oxford: Oxford University Press.

Ingvarson, L., Meiers, M. \& Beavis, A (2005) Factors Affecting the Impact of Professional Development Programs on Teachers' Knowledge, Practice, Student Outcomes and Efficacy, in Professional Development for Teachers and School Leaders. http://research.acer.edu.au/professional_dev/1

Musset, P. (2010) Initial Teacher Education and Continuing Training Policies in a Comparative Perspective: current practices in OECD countries and a literature review on potential effects, OECD Education Working Papers, No. 48. Paris: OECD Publishing. http://dx.doi.org/10.1787/5kmbphh7s47h-en

Number 10 (2010) http://www.number10.gov.uk/news/speeches-andtranscripts/2010/05/queens-speech-2010-2-50580

Quicke, J. (2000) A New Professionalism for a Collaborative Culture of Organisational Learning in a Contemporary Society, Educational Management and Administration, 28(3), 299-315.

Storey, A. (2009) How Fares the 'New Professionalism' in Schools? Findings from the 'State of the Nation' project, Curriculum Journal, 20(2), 121-138. http://dx.doi.org/10.1080/09585170902948806

Teacher Development Agency (TDA) http://www.tda.gov.uk/trainingprovider/itt/qts-standards-itt-requirements/guidance/qts-standards.aspx

The Times Educational Supplement (24 June 2011) New Down-to-Earth Courses for Heads Mean More Time in School.

http://www.tes.co.uk/article.aspx?storycode $=6090208$

Whitty, G. (2007) Teacher Professionalism in New Times, Journal of In-Service Education, 26(2), 281-282. http://dx.doi.org/10.1080/13674580000200137

JON BERRY is Senior Lecturer, UCU Branch Secretary, and CPD Admissions Tutor at the University of Hertfordshire, United Kingdom. Correspondence: j.berry@herts.ac.uk 